\title{
Elucidating the mechanisms of fear extinction in developing animals: a special case of NMDA receptor-independent extinction in adolescent rats
}

\author{
Madelyne A. Bisby, Kathryn D. Baker, and Rick Richardson \\ School of Psychology, UNSW Sydney, New South Wales, 2052, Australia
}

\begin{abstract}
NMDA receptors (NMDARs) are considered critical for the consolidation of extinction but recent work challenges this assumption. Namely, NMDARs are not required for extinction retention in infant rats as well as when extinction training occurs for a second time (i.e., reextinction) in adult rats. In this study, a possible third instance of NMDAR-independent extinction was tested. Although adolescents typically exhibit impaired extinction retention, rats that are conditioned as juveniles and then given extinction training as adolescents (JuvCond-AdolesExt) have good extinction retention. Unexpectedly, this good extinction retention is not associated with an up-regulation of a synaptic plasticity marker in the medial prefrontal cortex, a region implicated in extinction consolidation. In the current study, rats received either the noncompetitive NMDAR antagonist MK801 $(0.1 \mathrm{mg} / \mathrm{kg}$, s.c.) or saline before extinction training. In several experiments, rats conditioned and extinguished as juveniles, adolescents, or adults exhibited impaired extinction retention after MK80I compared to saline, but this effect was not observed in JuvCond-AdolesExt rats. Further experiments ruled out several alternative explanations for why NMDAR antagonism did not affect extinction retention in adolescents extinguishing fear learned as a juvenile. These results illustrate yet another circumstance in which NMDARs are not required for successful extinction retention and highlight the complexity of fear inhibition across development.
\end{abstract}

[Supplemental material is available for this article.]

The process of extinction, in which an animal learns to inhibit a previously conditioned response, has been a point of focus for behavioral neuroscientists over the past few decades (Milad and Quirk 2012). Numerous studies have shown that systemic administration of glutamatergic NMDA receptor (NMDAR) antagonists (e.g., MK801) before extinction training impairs the acquisition and retention of extinction, indicating that these receptors are critically involved in both the learning and the consolidation of extinction (Myers and Davis 2007; Davis 2011; Singewald et al. 2015). Some of this work has demonstrated that NMDARs in the amygdala are required for acquiring a new extinction memory, whereas NMDARs in the medial prefrontal cortex (mPFC) are involved in the subsequent consolidation of this memory (Falls et al. 1992; Burgos-Robles et al. 2007; Sotres-Bayon et al. 2007, 2009; Zimmerman and Maren 2010). Although most of this work has used adult rodents, studies in developing animals show that NMDARs are required for extinction retention in juvenile and adolescent rats (Langton et al. 2007; Baker and Richardson 2017).

However, the findings of other studies challenge the idea that NMDARs are always critical for extinction. For example, extinction retention in infant rats is insensitive to NMDAR antagonism (Langton et al. 2007; Kim and Richardson 2010). As another example, extinction training occurring for a second time (i.e., after reconditioning) is NMDAR-independent in adult rats (Chan and McNally 2009; Langton and Richardson 2010).

Recent work suggests that there may be a third instance of NMDAR-independent extinction, and this occurs during the transitional period of adolescence when there are significant changes

Corresponding author: m.bisby@unsw.edu.au

Article is online at http://www.learnmem.org/cgi/doi/10.1101/lm.047209. 117. to emotion and fear regulation (Casey et al. 2015). Adolescents, both rodent and human, exhibit impaired learning and/or retention of extinction of learned fear (e.g., Hefner and Holmes 2007; McCallum et al. 2010; Pattwell et al. 2012). However, adolescent rats successfully extinguish fear if it was acquired before adolescence. Baker and Richardson (2015) compared the extinction retention of adolescent rats for an auditory fear memory that was acquired either when the animal was a juvenile or an adolescent, with all animals undergoing extinction training in adolescence. Although adolescents exhibited impaired extinction of fear learned during adolescence, those animals initially conditioned as juveniles did not exhibit any impairment. Therefore, it would be predicted that these latter animals recruited activity-dependent cellular signaling cascades within the mPFC during extinction training. One such marker that is downstream from NMDARs and that leads to synaptic plasticity is the phosphorylation of mitogen activated protein kinase (pMAPK; English and Sweatt 1996; Sweatt 2004). Adolescents extinguishing fear learned as a juvenile did not exhibit an increase in the expression of pMAPK in the mPFC, a change usually observed in animals that exhibit good extinction retention (e.g., Kim et al. 2011). This finding suggests that there may be a third circumstance when the molecular mechanisms of successful extinction do not involve NMDAR-dependent pathways. In the present study we directly tested whether rats conditioned as juveniles and extinguished as adolescents require NMDARs for extinction retention through systemic

(C) 2018 Bisby et al. This article is distributed exclusively by Cold Spring Harbor Laboratory Press for the first 12 months after the full-issue publication date (see http://learnmem.cshlp.org/site/misc/terms.xhtml). After 12 months, it is available under a Creative Commons License (Attribution-NonCommercial 4.0 International), as described at http://creativecommons.org/licenses/by-nc/4.0/. 
administration of MK801 (a noncompetitive NMDAR antagonist) prior to extinction training.

\section{Results}

\section{Experiment 1}

Experiment 1 tested whether the extinction of fear acquired as a juvenile and extinguished as an adolescent is dependent on NMDARs. All rats received fear conditioning as juveniles on postnatal day (P) 24. Rats in one condition, JuvCond-Ext, received conditioning, extinction, and test on consecutive days (P24-26). Rats in the second condition, JuvCond-AdolesExt, were given extinction training and test $\sim 10 \mathrm{~d}$ later as adolescents, on P34-36 (see Fig. 1A for timeline). Animals in each condition were injected with MK801 (0.1 mg/kg, s.c.) or saline prior to extinction training.

\section{Results}

Baseline data and analysis for conditioning, extinction, and test across all experiments are presented in the Supplemental Methods and Supplemental Table S1. No systematic differences among the four groups in CS-elicited freezing across the three CS-US pairings during conditioning were found in this or the subsequent experiments (see Supplemental Fig. S1).

During extinction training, there was a significant effect of block $\left(F_{(2.84,168)}=40.50, P<0.001\right)$ and drug $\left(F_{(1,42)}=28.31, P<\right.$ 0.001 ; Fig. $1 \mathrm{~B})$. Further, there were two significant interactions: block $\times$ group $\left(F_{(2.84,168)}=3.00, P=0.04\right)$ and block $\times$ drug $\left(F_{(2.84,168)}=10.75, P<0.001\right)$. Due to the locomotor effects of the drug, MK801-treated rats had lower levels of freezing during extinction training than saline-treated rats. This effect did not differ between JuvCond-Ext and JuvCond-AdolesExt groups, indicating that MK801 had similar effects in both. While freezing decreased significantly over extinction blocks, saline-treated JuvCond-Ext rats extinguished at a faster rate than saline-treated JuvCondAdolesExt rats.

A

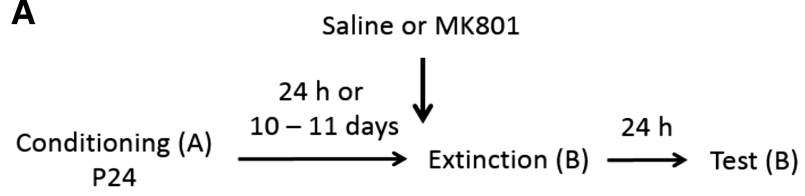

B
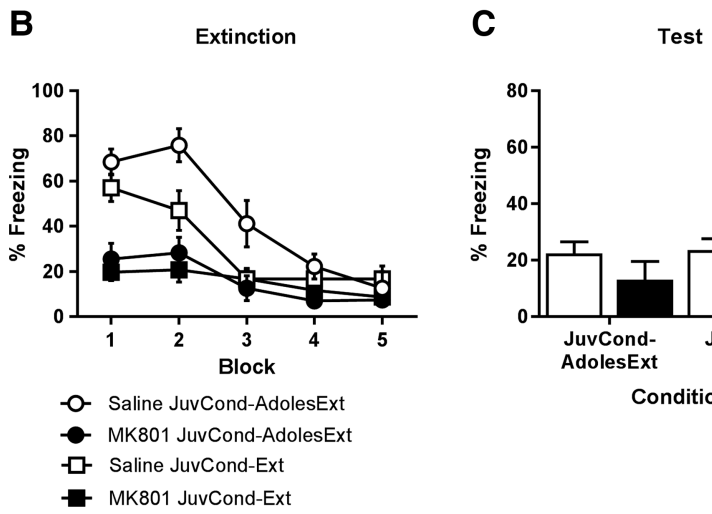

Figure 1. Experiment 1 timeline; the experimental contexts for conditioning, extinction, and test are denoted in parentheses $(A)$. Mean $( \pm$ SEM) levels of freezing at extinction training $(B)$, and extinction retention test (C) for groups Saline JuvCond-AdolesExt $(n=12)$, MK801 JuvCond-AdolesExt $(n=12)$, Saline JuvCond-Ext $(n=11)$, and MK801 JuvCond-Ext $(n=11)$. * Indicates a significant difference $(P<0.05)$.
At test, there was a significant effect of group $\left(F_{(1,42)}=8.54, P\right.$ $=0.006)$ as well as a group $\times$ drug interaction $\left(F_{(1,42)}=7.09, P=0.01\right.$; Fig. 1C). The interaction was due to MK801 impairing extinction retention in rats trained and extinguished as juveniles (MK801 versus SAL: $t_{(20)}=2.67$ [95\% CI, 4.05-32.77], $P=0.02$ ) but not in rats trained as juveniles and extinguished as adolescents (MK801 versus SAL: $\left.t_{(22)}=1.20[95 \% \mathrm{CI},-25.01-6.68], P>0.05\right)$. An additional experiment confirmed that NMDAR-independent extinction in rats conditioned as juveniles at P26 and extinguished as adolescents at P32, suggesting that the results above are not due to a specific 10-d interval or conditioning at P24 (see Supplemental Fig. S2). These findings suggest that NMDARs are not involved in extinction in adolescent rats that acquired fear as juveniles, even though these animals exhibited good extinction retention.

\section{Experiment 2}

While the results of Experiment 1 show that NMDARs were not engaged in extinction in adolescent rats that learned the CS-US association as juveniles, the comparison group was a group of juvenile rats. In this experiment, we compared two groups of adolescent rats. Typically, rats conditioned and extinguished as adolescents exhibit impaired extinction retention when given the same amount of extinction training (i.e., 30 trials) as occurred in Experiment 1 (e.g., McCallum et al. 2010). When rats conditioned as adolescents receive extended extinction training (e.g., $2 \mathrm{~d}, 30$ trials per day), this leads to improved extinction retention (Den et al. 2014; Baker and Richardson 2017). Further, adolescent rats recruit NMDARs under these conditions, as systemic administration of MK801 prior to the second extinction session blocks this improvement in extinction retention (Baker and Richardson 2017). Therefore, in Experiment 2 we compared the effects of MK801 administration on extinction in adolescent rats that acquired fear as juveniles to that of adolescent rats that acquired fear as adolescents, under conditions in which both would exhibit good extinction retention. This experiment tested the prediction that when extinction is successful in adolescence it is not always dependent upon NMDARs; that is, when fear is learned as a juvenile, then good extinction retention in adolescence does not require NMDARs.

To achieve good extinction retention across groups, animals trained as adolescents received $2 \mathrm{~d}$ of extinction training while those trained as juveniles received $1 \mathrm{~d}$ of extinction training (see Fig. 2A). Animals in the AdolesCond-Ext condition were injected with MK801 or saline on the second day of extinction training while animals in the JuvCond-AdolesExt condition were injected on the single day of extinction training. In both conditions, the final extinction training session occurred $24 \mathrm{~h}$ prior to test. The procedures followed those in Experiment 1 with the exception that the shock intensity during conditioning was increased from 0.4 to $0.5 \mathrm{~mA}$ to test the generality of the findings of Experiment 1 while also reducing the likelihood of floor effects at test. As expected, freezing in both groups during CS-US acquisition at conditioning was higher than in Experiment 1 (Supplemental Fig. S1).

\section{Results}

The first day of extinction training proceeded as expected (Fig. 2B). Both groups conditioned as adolescents showed evidence of within-session extinction $\left(F_{(2.87,60.28)}=36.13, P<0.001\right)$. There were no differences between groups that were to be injected with saline or MK801 the following day (group main effect $F_{(1,21)}=$ 1.70, $P=0.20$; group $\times$ trial interaction $F<1$ ).

Across the second day of extinction, where all four groups received extinction training, there was a decrease of levels of CS-elicited freezing over blocks $\left(F_{(3.12,159.08)}=68.70, P<0.001\right)$. As in the previous experiment, MK801-treated animals had lower levels of CS-elicited freezing (drug main effect $F_{(1,51)}=33.36, P<$ 

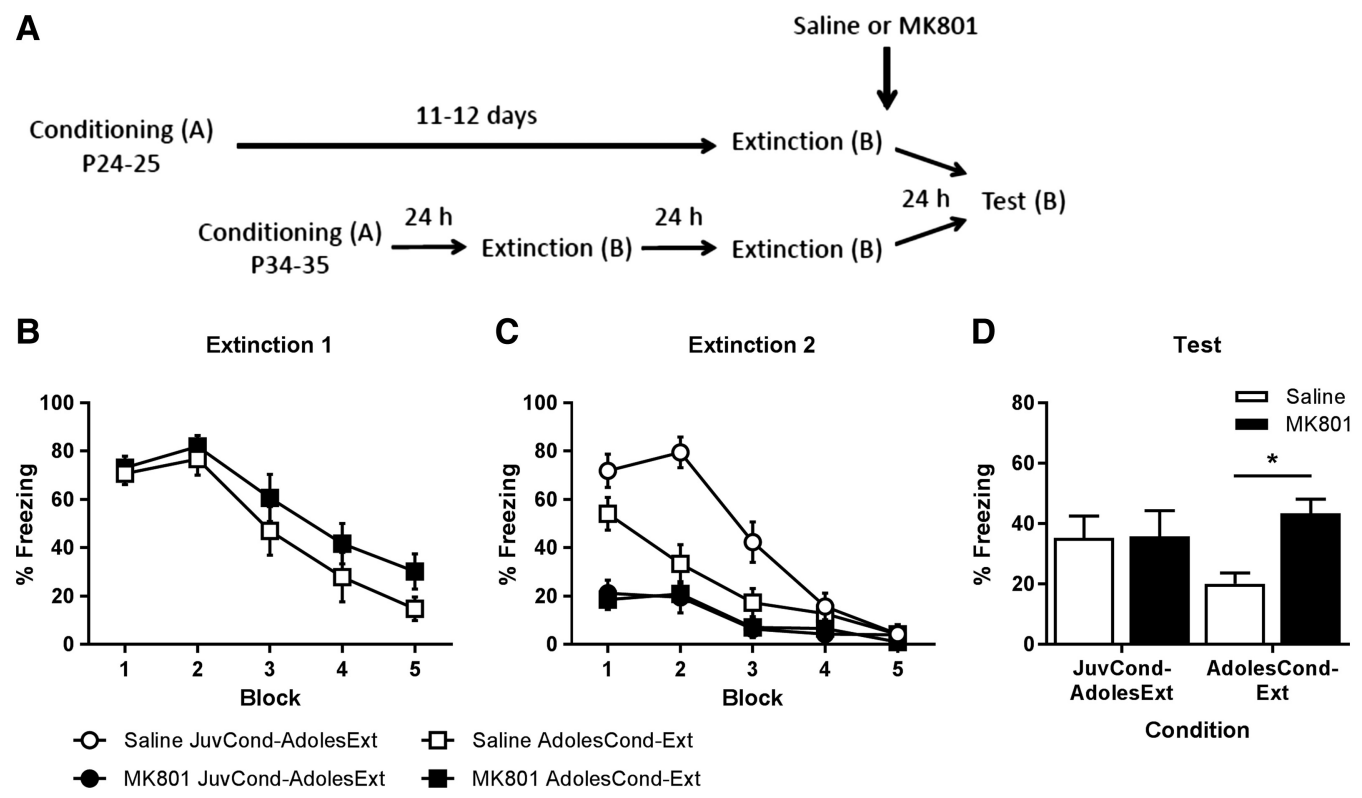

Figure 2. Experiment 2 timeline; the experimental contexts for conditioning, extinction, and test are denoted in parentheses $(A)$. Mean $( \pm$ SEM) levels of freezing at extinction training day $1(B)$, and extinction training day $2(C)$, and extinction retention test $(D)$ for groups Saline JuvCond-AdolesExt $(n=16)$, MK801 JuvCond-AdolesExt $(n=16)$, Saline AdolesCond-Ext $(n=11)$, and MK801 AdolesCond-Ext $(n=12) .{ }^{*}$ Indicates a significant difference $(P<0.05)$.

0.001 ; drug $\times$ block interaction $F_{(3.12,159.08)}=18.29, P<0.001$; Fig. 2C). The three-way mixed-model ANOVA revealed a significant effect of condition $\left(F_{(1,51)}=5.70, P=0.021\right)$, condition $\times$ drug interaction $\left(F_{(1,51)}=5.42, P=0.024\right)$, a condition $\times$ block interaction $\left(F_{(3.12,159.08)}=4.77, P=0.003\right)$, and a condition $\times$ drug $\times$ block interaction $\left(F_{(3.12,159.08)}=18.29, P=0.001\right)$. Not surprisingly, these analyses confirmed that there was a "savings effect." That is, AdolesCond-Ext rats, in the saline group, had overall lower levels of freezing and extinguished faster during their second day of extinction training compared to the JuvCond-AdolesExt rats, in the saline group, on their first day of extinction training.

Figure $2 \mathrm{D}$ depicts group performances at test. All salinetreated rats exhibited good extinction retention, regardless of their age at conditioning. As predicted, MK801 impaired extinction retention in those rats conditioned as adolescents, and given $2 \mathrm{~d}$ of extinction training, but did not impair extinction retention in the rats conditioned as juveniles and then extinguished as adolescents. This description of the data was confirmed by analyses. Specifically, replicating the results of Experiment 1, but with a higher shock intensity in training, rats conditioned as juveniles but extinguished as adolescents (i.e., Groups JuvCond-AdolesExt) exhibited good extinction retention regardless of whether they were injected with MK801 or not $\left(t_{(29.22)}=0.04\right.$ [95\% CI, -22.3623.30], $P=0.97)$. As was reported by Baker and Richardson (2017), for those rats conditioned and extinguished as adolescents (i.e., Groups AdolesCond-Ext) giving $2 \mathrm{~d}$ of extinction only resulted in good extinction retention in those injected with saline whereas animals given the NMDAR antagonist exhibited impaired extinction retention $\left(t_{(19.97)}=3.90\right.$ [95\% CI, 10.87-35.80], $P=$ 0.001).

\section{Experiment 3}

The findings of Experiments 1 and 2 show that adolescent rats that acquired fear as juveniles use an NMDAR-independent process to extinguish that fear, in contrast to animals trained and extinguished as juveniles (Experiment 1) or those trained and extinguished as adolescents (Experiment 2). However, the animals trained as juveniles and extinguished as adolescents had a 10-12 $\mathrm{d}$ delay between the conditioning and extinction sessions, while the comparison groups in both of the first two experiments only had a $1 \mathrm{~d}$ delay between sessions. Experiment 3 examined whether the introduction of a delay converts extinction into a NMDAR-independent process, regardless of the animal's age. To test this possibility, adult rats were conditioned and then extinguished with either a 1 or 10 d delay between the two sessions. As in Experiment 1, the shock intensity used at conditioning was $0.4 \mathrm{~mA}$. Half of the animals at each interval were injected with MK801 prior to extinction training while the others were injected with saline (see Fig. 3A).

\section{Results}

Given group differences in baseline freezing levels at extinction (see the Supplemental Methods for details), it was used as a covariate in the analysis of CS-elicited freezing during extinction training. There was a significant effect of block $\left(F_{(2.43,108)}=15.44, P<\right.$ 0.001 ; see Fig. 3B), as CS-elicited freezing decreased over the course of extinction training. In addition, there was a significant effect of $\operatorname{drug}\left(F_{(1,27)}=39.15, P<0.001\right)$, due to the MK801-treated rats exhibiting less freezing than saline-treated rats, as in the previous experiments. The drug $\times$ block interaction was also significant $\left(F_{(2.43,108)}=13.28, P<0.001\right)$, due to the MK801- and saline-treated rats exhibiting different levels of freezing at the start of extinction training but similar levels by the end. A delay between conditioning and extinction sessions did not affect within-session extinction (main effect of interval and the interval $\times$ drug interaction Fs $<1)$.

Figure 3C shows that at test, MK801-treated rats had higher levels of CS-elicited freezing than saline-treated controls. This description of the data was supported by the statistical analysis which showed a significant effect of drug treatment $\left(F_{(1,28)}=\right.$ $8.47, P=0.007)$. The effect of delay between conditioning and extinction, as well as the interval $\times$ drug interaction were not significant $(F s<1)$. Therefore, introducing a $10 \mathrm{~d}$ delay between 


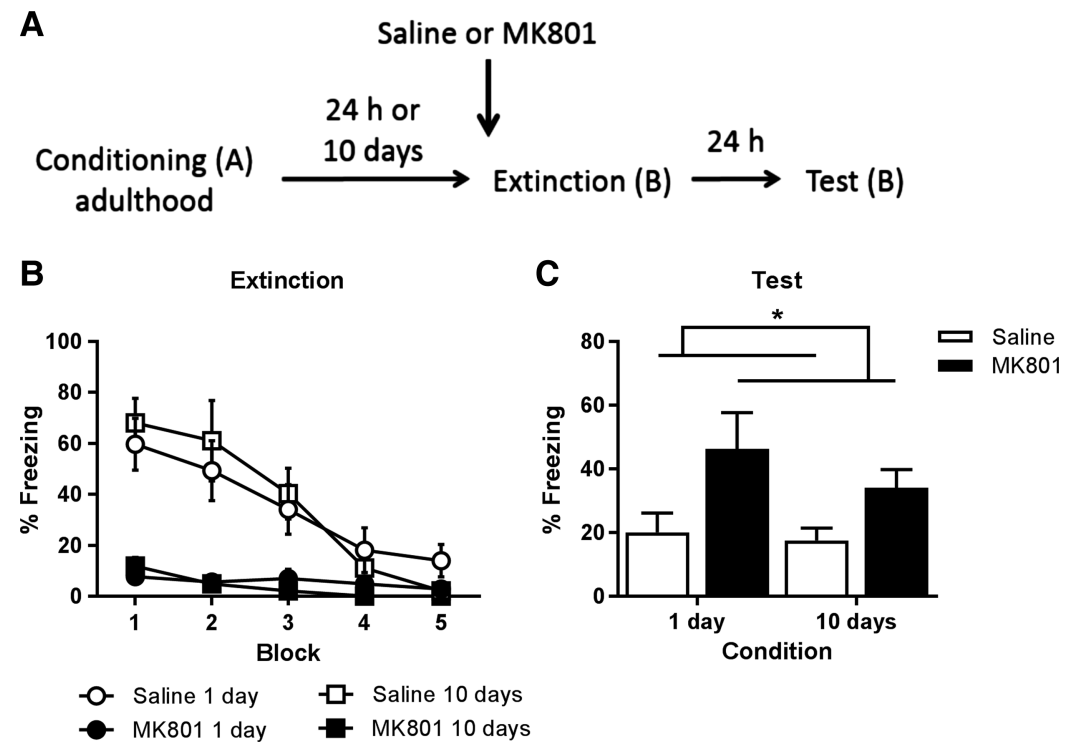

Figure 3. Experiment 3 timeline $(A)$; the experimental contexts for conditioning, extinction, and test are denoted in parentheses. Mean $( \pm$ SEM) levels of freezing at extinction training $(B)$, and extinction retention test $(C)$ for groups Saline $1 \mathrm{~d}(n=8)$, MK801 $1 \mathrm{~d}(n=8)$, Saline $10 \mathrm{~d}(n=8)$, and MK801 $10 \mathrm{~d}(n=$ $8)$. * Indicates a significant difference $(P<0.05)$.

conditioning and extinction sessions does not lead to a switch to an NMDAR-independent form of extinction, at least in adult rats.

\section{Experiment 4}

The findings of Experiment 3 show that merely having a $10 \mathrm{~d}$ delay between conditioning and extinction does not lead to extinction becoming NMDAR-independent. Another possible reason for our observation of extinction being NMDAR-independent in rats conditioned as juveniles and extinguished as adolescents is that maturation from one developmental stage into another leads to such a switch. That is, extinction may be NMDAR-independent when animals undergo conditioning and extinction in different stages of development. To test this possibility, in Experiment 4 rats received conditioning as adolescents but extinction as adults (see Fig. 4A).

\section{Results}

There was a group difference in pre-CS freezing levels in the extinction phase (see Supplemental Methods), therefore baseline freezing was included as a covariate in the analysis of extinction training. There was a main effect of block $\left(F_{(2.67,88)}=10.81, P<\right.$ $0.001)$, drug $\left(F_{(1,22)}=15.31, P=0.001\right)$, and a block $\times$ drug interaction $\left(F_{(2.67,88)}=5.10, P=0.005\right)$. The drug effect was a result of the rats given MK801 having lower overall levels of freezing than rats that received saline and the interaction was due to the two drug groups performing differently at the start of extinction training but similarly by the end (Fig. 4B).

At test, rats given MK801 had higher levels of CS-elicited freezing than rats that received saline prior to extinction $\left(t_{(14.61)}=2.41\right.$ [95\% CI, 2.62-44.24], $P=0.03$; Fig. 4C). Therefore, the transition from adolescence to adulthood did not change the involvement of NMDARs in extinction, suggesting that it is not the experience of a developmental transition alone that causes extinction to be NMDAR-independent in adolescent rats that acquired fear as juveniles (Experiments 1 and 2).

\section{Discussion}

Although adolescents are typically impaired at extinction (McCallum et al. 2010; Pattwell et al. 2012; Ganella et al. 2017), Baker and Richardson (2015) reported a circumstance in which they exhibit extinction retention equivalent to that observed in either younger or older animals. That is, rats that acquire fear when a juvenile and then extinguish that fear as an adolescent show good extinction retention. However, these animals do not use the same prefrontalamygdala neural circuit as juvenile and adult rats to successfully extinguish fear (Baker and Richardson 2015). In the present study, we illustrated another unique element of fear inhibition in this groupnamely, that NMDARs are not required for successful extinction.

The NMDAR-independent extinction of rats conditioned as juveniles and extinguished as adolescents was in stark contrast to the NMDA-dependent extinction of rats conditioned and extinguished as juveniles (Experiment 1), adolescents (Experiment 2), or adults (Experiment 3). The reduced involvement of NMDARs in extinction was not a consequence of the delay between conditioning and extinction in adolescent rats that acquired fear as juveniles, as blocking NMDARs at extinction still caused poor extinction retention in adult rats despite the introduction of a similar delay (Experiment 3). Last, antagonizing NMDARs prior to extinction training in rats conditioned as adolescents and extinguished as adults impaired extinction retention (Experiment 4), indicating that the transition between developmental phases was not responsible for the NMDAR-independent extinction observed in animals conditioned as juveniles and extinguished as adolescents. Together,

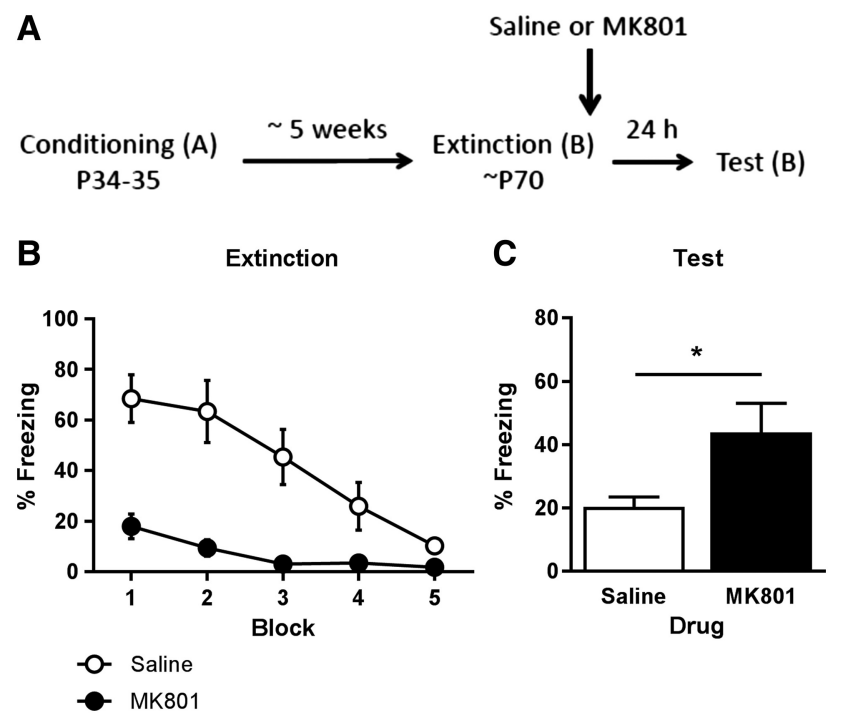

Figure 4. Experiment 4 timeline $(A)$; the experimental contexts for conditioning, extinction, and test are denoted in parentheses. Mean $( \pm S E M)$ levels of freezing at extinction training $(B)$, and extinction retention test (C) for groups Saline $(n=12)$ and MK801 $(n=13) .{ }^{*}$ Indicates a significant difference $(P<0.05)$. 
these experiments highlight not only the qualitatively different nature of extinction across development, but also question the notion that NMDARs are necessary for acquiring extinction.

Although MK801 is primarily an NMDAR antagonist, it has some actions as a nicotinic acetylcholine receptor antagonist (Ramoa et al. 1990; Amador and Dani 1991). However, MK801 has much more potency (around 100 times) at NMDARs than nicotine receptors (Briggs and McKenna 1996; Löscher et al. 2003) and has little effect on nicotine responses when used behaviorally (Zakharova et al. 2005). Therefore, it is possible, but unlikely, that some of the MK801's effects are due to antagonistic actions on acetylcholine receptors. However, even considering the possibility that non-NMDARs could be blocked during extinction training in juvenile and adult animals, our results still indicate that the neural mechanisms of extinction in rats conditioned as juveniles and extinguished as adolescents differ to animals of other ages.

Further highlighting the unique extinction in rats conditioned as juveniles and extinguished as adolescents is the fact that the mechanisms underlying other circumstances of NMDAR-independent extinction do not easily explain why extinction is NMDAR-independent in this circumstance. In the case of reextinction in adult rats, it has been proposed that NMDARs are not required as this involves the recall and subsequent reconsolidation of the original extinction memory rather than the formation of a new extinction memory. However, rats conditioned as juveniles and extinguished as adolescents cannot retrieve a prior memory of extinction as this is the first instance when they receive extinction training. Considering another instance of NMDAR-independent extinction, it has been proposed that the immaturity of the prefrontal cortex during infancy contributes to NMDAR-independent extinction at that age. This conclusion was based on the finding that temporary inactivation of the mPFC (using bupivacaine, a sodium channel modulator) during extinction training did not affect extinction retention in infant rats, unlike juvenile rats (Kim et al. 2009). Given that the mPFC is involved in extinction in juveniles, and that adolescents can use NMDARs for extinction (Experiment 2), the explanation that the mPFC is immature does not account for why extinction was NMDAR-independent in adolescent rats simply because they acquired fear as juveniles. In contrast, temporary inactivation of the basolateral amygdala (BLA) does result in extinction memory deficits in infant rats (Kim and Richardson 2008), suggesting that this region is sufficiently mature to support extinction in infants. Future studies could investigate whether temporary inactivation, or chemogenetic inhibition, of the amygdala during extinction training produces extinction retention deficits in adolescents extinguishing fear learned as a juvenile. If so, such findings would suggest that the amygdala supports NMDAR-independent extinction under at least two circumstances during development. However, it is also possible that no deficit would be detected following amygdala inactivation, considering that we previously found that pMAPK was not up-regulated in the BLA in adolescents extinguishing fear learned as a juvenile (Baker and Richardson 2015). Taken together, such findings would provide further evidence of unique extinction mechanisms in adolescents.

One basis for our prediction that NMDARs would have been involved in extinction in those animals trained as juveniles and then extinguished as adolescents was the findings from a body of work examining how memories are acquired and then expressed in different developmental stages. Those studies demonstrated that an animal's age at acquisition determines how the learned fear is later expressed. For example, rats trained as infants and tested as juveniles express fear in a manner appropriate to their age at training, not test (Richardson and Fan 2002; Barnet and Hunt 2006). In addition, these animals do not use the neural structures that have matured since the time of memory encoding. Juveniles use the prelimbic mPFC to retrieve/express fear that was learned during the juvenile developmental stage, but not if that memory was learned during infancy when this region was immature (Li et al. 2012). However, rats trained as juveniles and extinguished as adolescents do not use NMDARs, or show pMAPK expression in the prefrontal cortex, during extinction-two features of the neural system that was in place when they acquired the fear as juvenile animals (Langton et al. 2007; Baker and Richardson 2015). That being said, the brain undergoes quite different neurodevelopmental changes during the juvenile to adolescent transition compared to the infant to juvenile transition (e.g., the balance of synaptic pruning and synaptic growth; Semple et al. 2013). As such, it may be the case that the experience of one developmental transition has different effects on how previously acquired memories are inhibited compared to the other.

The question remains open, then, of how extinction memories are formed and consolidated in animals undergoing a transition between the juvenile period and adolescence, as well as the different neurobiological mechanisms that must be involved. Several neurotransmitters may take a more pronounced role in this circumstance. One potential candidate is the endocannabinoid system, which is involved in the regulation of learning and memory processes, including extinction, in adult rats (for reviews, see Mechoulam and Parker 2013; Morena and Campolongo 2014). While pharmacological augmentation of cannabinoid receptor 1 or its endogenous ligand anandamide facilitates extinction, genetic knockout or pharmacological blockade of cannabinoid receptor 1 impairs extinction (e.g., Marsicano et al. 2002; Pamplona et al. 2008; Gunduz-Cinar et al. 2013; Bowers and Ressler 2015). Another possibility involves metabotropic glutamate 5 receptors, which have been shown to be involved in extinction in adolescent rodents (e.g., Sepulveda-Orengo et al. 2013). Future research examining how one, or several, of these alternative neurobiological mechanisms are involved in extinction in NMDAR-independent extinction is warranted.

Over the past several decades, substantial progress has been made delineating the molecular, cellular, and systems-level processes involved in extinction. An important piece of this puzzle has been the assertion that NMDARs are critically involved, a claim with substantial empirical evidence. However, the small, but growing, body of work demonstrating that extinction can effectively occur without NMDARs, both in developing animals and in adults, highlights the need for continued research into the role of NMDARs in extinction. There must be different neurobiological mechanisms facilitating inhibition of learned fear in these circumstances, and a greater understanding of these alternative neurobiological mechanisms will improve our models of extinction and as a result, may provide opportunities for more effective and targeted treatments for anxiety disorders.

\section{Materials and Methods}

\section{Subjects}

This study involved 160 experimentally naive Sprague-Dawley male rats (see Supplemental Methods). All animals were treated in accordance with the Australian Code of Practice for the Care and Use of Animals for Scientific Purposes (8th Edition, 2013), and all procedures were approved by the Animal Care and Ethics Committee at UNSW.

\section{Procedure and statistical analysis}

The apparatus and behavioral procedures were similar to those we have previously used in studies on extinction (see McCallum et al. 2010; Baker et al. 2013; Baker and Richardson 2015). In each experiment, rats received Pavlovian conditioning, extinction, and test (see experimental timelines in Figs. 1-4 for details). 
Two sets of distinctive chambers were used, with fear conditioning occurring in Context $\mathrm{A}$, and extinction training and retention testing occurring in Context B (see the Supplemental Methods). During extinction training, 6 trials were averaged to represent 1 block of extinction. Animals were tested the day after extinction with a single CS presented for $2 \mathrm{~min}$.

The behavior of the rats was scored as freezing or not freezing every 3 sec during the adaptation (pre-CS) period and the CS presentations. Freezing was scored for any observation where there was the absence of all movement other than that required for respiration (Fanselow 1994). A random sample of $\sim 30 \%$ of the test data was cross-scored by an observer unaware of the experimental conditions. Inter-rater reliability was high for all experiments $(r=0.93-0.98)$. Freezing was analyzed by ANOVA and $t$-tests (Supplemental Methods).

\section{Drugs}

(+)-MK 801 maleate (Tocris Bioscience; $0.1 \mathrm{mg} / \mathrm{kg}$ ) or saline was administered subcutaneously (in the nape of the neck) in a volume of $1 \mathrm{~mL} / \mathrm{kg}, 10 \mathrm{~min}$ before extinction, as in past studies (Langton and Richardson 2010; Chan et al. 2015; Baker and Richardson 2017). MK801 reaches maximal brain concentrations 10 to 30 min after systemic injection in the rat (Vezzani et al. 1989).

\section{Acknowledgments}

This research was supported by grants from the National Health and Medical Research Council (NHMRC; APP1086855 to RR and $\mathrm{KB}$ ) and the Australian Research Council (ARC; DP150104835 to $\mathrm{RR}) . \mathrm{MB}$ is supported by an Australian Postgraduate Award. KB was supported by a NHMRC Peter Doherty Early Career Fellowship (APP1054642) and then an ARC Discovery Early Career Researcher Award (DE170100392). The authors have no conflicts of interest to declare.

ReferencesAmador M, Dani JA. 1991. MK-801 inhibition of nicotinic acetylcholine receptor channels. Synapse 7: 207-215.

Baker KD, Richardson R. 2015. Forming competing fear learning and extinction memories in adolescence makes fear difficult to inhibit. Learn Mem 22: 537-543.

Baker KD, Richardson R. 2017. Pharmacological evidence that a failure to recruit NMDA receptors contributes to impaired fear extinction retention in adolescent rats. Neurobiol Learn Mem 143: 18-26.

Baker KD, McNally GP, Richardson R. 2013. Memory retrieval before or after extinction reduces recovery of fear in adolescent rats. Learn Mem 20: 467-473.

Barnet RC, Hunt PS. 2006. The expression of fear-potentiated startle during development: integration of learning and response systems. Behav Neurosci 120: 861-872.

Bowers ME, Ressler KJ. 2015. Interaction between the cholecystokinin and endogenous cannabinoid systems in cued fear expression and extinction retention. Neuropsychopharmacology 40: 688-700.

Briggs CA, McKenna DG. 1996. Effect of MK-801 at the human $\alpha 7$ nicotinic acetylcholine receptor. Neuropharmacology 35: 407-414.

Burgos-Robles A, Vidal-Gonzalez I, Santini E, Quirk GJ. 2007. Consolidation of fear extinction requires NMDA receptor-dependent bursting in the ventromedial prefrontal cortex. Neuron 53: 871-880.

Casey BJ, Glatt CE, Lee FS. 2015. Treating the developing versus developed brain: translating preclinical mouse and human studies. Neuron 86: 1358-1368.

Chan WY, McNally GP. 2009. Conditioned stimulus familiarity determines effects of MK-801 on fear extinction. Behav Neurosci 123: 303-314.

Chan D, Baker KD, Richardson R. 2015. Relearning a context-shock association after forgetting is an NMDAr-independent process. Physiol Behav 148: 29-35

Davis M. 2011. NMDA receptors and fear extinction: implications for cognitive behavioral therapy. Dialogues Clin Neurosci 13: 463-474.

Den ML, Altmann SR, Richardson R. 2014. A comparison of the short- and long-term effects of corticosterone exposure on extinction in adolescence versus adulthood. Behav Neurosci 128: 722-735.

English JD, Sweatt JD. 1996. Activation of p42 mitogen-activated protein kinase in hippocampal long term potentiation. J Biol Chem 271: 24329-24332.
Falls WA, Miserendino MJ, Davis M. 1992. Extinction of fear-potentiated startle: blockade by infusion of an NMDA antagonist into the amygdala. J Neurosci 12: 854-863.

Fanselow MS. 1994. Neural organization of the defensive behavior system responsible for fear. Psychon Bull Rev 1: 429-438.

Ganella DE, Lee-Kardashyan L, Luikinga SJ, Nguyen DLD, Madsen HB, Zbukvic IC, Coulthard R, Lawrence AJ, Kim JH. 2017. Aripiprazole facilitates extinction of conditioned fear in adolescent rats. Front Behav Neurosci 11: 76.

Gunduz-Cinar O, MacPherson K, Cinar R, Gamble-George J, Sugden K, Williams B, Godlewski G, Ramikie TS, Gorka AX, Alapafuja SO, et al. 2013. Convergent translational evidence of a role for anandamide in amygdala-mediated fear extinction, threat processing and stressreactivity. Mol Psychiatry 18: 813-823.

Hefner K, Holmes A. 2007. Ontogeny of fear-, anxiety- and depressionrelated behavior across adolescence in C57BL/6J mice. Behav Brain Res 176: $210-215$.

Kim J H, Richardson R. 2008. The effect of temporary amygdala inactivation on extinction and reextinction of fear in the developing rat: unlearning as a potential mechanism for extinction early in development. J Neurosci 28: $1282-1290$.

Kim JH, Richardson R. 2010. Extinction in preweanling rats does not involve NMDA receptors. Neurobiol Learn Mem 94: 176-182.

Kim JH, Hamlin AS, Richardson R. 2009. Fear extinction across development: the involvement of the medial prefrontal cortex as assessed by temporary inactivation and immunohistochemistry. $J$ Neurosci 29: 10802-10808.

Kim JH, Li S, Richardson R. 2011. Immunohistochemical analyses of longterm extinction of conditioned fear in adolescent rats. Cereb Cortex 21: $530-538$.

Langton JM, Richardson R. 2010. The temporal specificity of the switch from NMDAr-dependent extinction to NMDAr-independent re-extinction. Behav Brain Res 208: 646-649.

Langton JM, Kim JH, Nicholas J, Richardson R. 2007. The effect of the NMDA receptor antagonist MK-801 on the acquisition and extinction of learned fear in the developing rat. Learn Mem 14: 665-668.

Li S, Kim JH, Richardson R. 2012. Updating memories: changing the involvement of the prelimbic cortex in the expression of an infant fear memory. Neuroscience 222: $316-325$.

Löscher W, Potschka H, Wlaź P, Danysz W, Parsons CG. 2003. Are neuronal nicotinic receptors a target for antiepileptic drug development? Studies in different seizure models in mice and rats. Eur J Pharmacol 466: $99-111$

Marsicano G, Wotjak CT, Azad SC, Bisogno T, Rammes G, Cascio MG, Hermann H, Tang J, Hofmann C, Zieglgänsberger W, et al.2002. The endogenous cannabinoid system controls extinction of aversive memories. Nature 418: 530-534.

McCallum J, Kim JH, Richardson R. 2010. Impaired extinction retention in adolescent rats: effects of D-cycloserine. Neuropsychopharmacology 35: 2134-2142

Mechoulam R, Parker LA. 2013. The endocannabinoid system and the brain. Annu Rev Psychol 64: 21-47.

Milad MR, Quirk GJ. 2012. Fear extinction as a model for translational neuroscience: ten years of progress. Annu Rev Psychol 63: $129-151$.

Morena M, Campolongo P. 2014. The endocannabinoid system: an emotional buffer in the modulation of memory function. Neurobiol Learn Mem 112: 30-43.

Myers KM, Davis M. 2007. Mechanisms of fear extinction. Mol Psychiatry 12: 120-150.

Pamplona FA, Bitencourt RM, Takahashi RN. 2008. Short- and long-term effects of cannabinoids on the extinction of contextual fear memory in rats. Neurobiol Learn Mem 90: 290-293.

Pattwell SS, Duhoux S, Hartley CA, Johnson DC, Jing D, Elliott MD, Ruberry EJ, Powers A, Mehta N, Yang RR, et al.2012. Altered fear learning across development in both mouse and human. Proc Natl Acad Sci 109: $16318-16323$.

Ramoa AS, Alkondon M, Aracava Y, Irons J, Lunt GG, Deshpande SS, Wonnacott S, Aronstam RS, Albuquerque EX. 1990. The anticonvulsant MK-801 interacts with peripheral and central nicotonic acetylcholine receptor ion channels. J Pharmacol Exp Ther 254: $71-82$.

Richardson R, Fan M. 2002. Behavioral expression of learned fear in rats is appropriate to their age at training, not their age at testing. Anim Learn Behav 30: 394-404.

Semple BD, Blomgren K, Gimlin K, Ferriero DM, Noble-Haeusslein LJ. 2013. Brain development in rodents and humans: identifying benchmarks of maturation and vulnerability to injury across species. Prog Neurobiol 106-107: 1-16.

Sepulveda-Orengo MT, Lopez AV, Soler-Cedeño O, Porter JT. 2013. Fear extinction induces mGluR5-mediated synaptic and intrinsic plasticity in infralimbic neurons. J Neurosci 33: 7184-7193. 
Singewald N, Schmuckermair C, Whittle N, Holmes A, Ressler KJ. 2015. Pharmacology of cognitive enhancers for exposure-based therapy of fear, anxiety and trauma-related disorders. Pharmacol Ther 149: 150-190.

Sotres-Bayon F, Bush DE, LeDoux JE. 2007. Acquisition of fear extinction requires activation of NR2B-containing NMDA receptors in the lateral amygdala. Neuropsychopharmacology 32: 1929-1940.

Sotres-Bayon F, Diaz-Mataix L, Bush DE, LeDoux JE. 2009. Dissociable roles for the ventromedial prefrontal cortex and amygdala in fear extinction: NR2B contribution. Cereb Cortex 19: 474-482.

Sweatt JD. 2004. Mitogen-activated protein kinases in synaptic plasticity and memory. Curr Opin Neurobiol 14: 311-317.
Vezzani A, Serafini R, Stasi M, Caccia S, Conti I, Tridico R, Samanin R. 1989. Kinetics of MK-801 and its effect on quinolinic acid-induced seizures and neurotoxicity in rats. J Pharmacol Exp Ther 249: 278-283.

Zakharova ES, Danysz W, Bespalov AY. 2005. Drug discrimination analysis of NMDA receptor channel blockers as nicotinic receptor antagonists in rats. Psychopharmacology (Berl) 179: 128-135.

Zimmerman JM, Maren S. 2010. NMDA receptor antagonism in the basolateral but not central amygdala blocks the extinction of Pavlovian fear conditioning in rats. Eur J Neurosci 31: 1664-1670.

Received December 2, 2017; accepted in revised form December 29, 2017. 


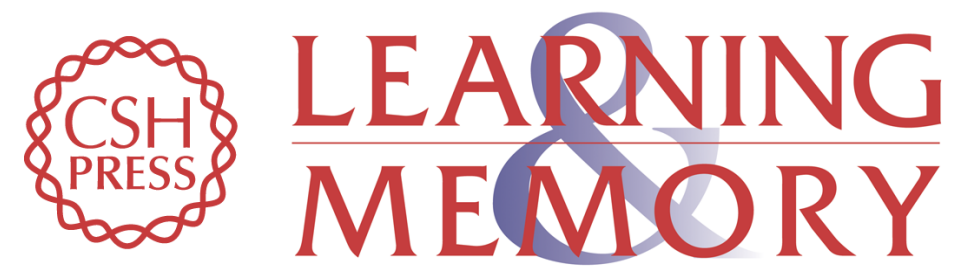

\section{Elucidating the mechanisms of fear extinction in developing animals: a special case of NMDA receptor-independent extinction in adolescent rats}

Madelyne A. Bisby, Kathryn D. Baker and Rick Richardson

Learn. Mem. 2018, 25:

Access the most recent version at doi:10.1101/lm.047209.117

\section{Supplemental http://learnmem.cshlp.org/content/suppl/2018/03/07/25.4.158.DC1 \\ Material}

References

Creative Commons License

Email Alerting Service
This article cites 46 articles, 11 of which can be accessed free at: http://learnmem.cshlp.org/content/25/4/158.full.html\#ref-list-1

This article is distributed exclusively by Cold Spring Harbor Laboratory Press for the first 12 months after the full-issue publication date (see http://learnmem.cshlp.org/site/misc/terms.xhtml). After 12 months, it is available under a Creative Commons License (Attribution-NonCommercial 4.0 International), as described at http://creativecommons.org/licenses/by-nc/4.0/.

Receive free email alerts when new articles cite this article - sign up in the box at the top right corner of the article or click here. 